\title{
Incidence, Predictors, and Strategies for Failure of Retrograde Microcatheter Tracking After Successful Wiring of Septal Collateral Channels in Chronic Total Occlusions
}

This article was published in the following Dove Press journal:

Clinical Interventions in Aging

\section{Yong Wang (D) \\ Xiao-jiao Zhang \\ Hong-wei Zhao \\ Chengfu Wang \\ Defeng Luo \\ Qingkun Meng \\ Yu Zhu \\ Jie Tao \\ Baojun Chen \\ Yi Li \\ Aijie Hou \\ Bo Luan}

Department of Cardiology, The People's Hospital of China Medical University, The People's Hospital of Liaoning Province, Shenyang City, Liaoning Province I10016, People's Republic of China
Correspondence: Bo Luan; Aijie Hou Department of Cardiology, The People's Hospital of China Medical University, The People's Hospital of Liaoning Province, No. 33, Wenyi Road, Shenhe District, Shenyang City, Liaoning Province II0016, People's Republic of China

Tel +86-17702488970

Email luanbo2016@163.com;

1758624242@qq.com
Background: Retrograde microcatheter collateral channel (CC) tracking after successful wiring of septal $\mathrm{CC}$ is crucial for retrograde revascularization of coronary chronic total occlusion (CTO). However, the incidence, predictors, and strategies for failure of retrograde microcatheter $\mathrm{CC}$ tracking after successful wiring of septal $\mathrm{CC}$ remain unclear.

Methods: In total, 298 patients with CTO who underwent retrograde septal CC PCI between January 2015 and May 2019 were retrospectively analyzed. Clinical data were compared to investigate the predictors of initial microcatheter tracking failure.

Results: The initial and final microcatheter tracking success rates were 79.2\% (236/298) and 96.6\% (288/298), respectively. The procedural success rate was 94.0\% (280/298). The right coronary artery-to-left anterior descending artery septal ratio ( $48.4 \%$ vs $33.1 \%, \mathrm{p}=0.037)$ and CC tortuosity $(34.6 \%$ vs $20.8 \%, \mathrm{p}=0.045)$ were significantly higher in the initial microcatheter $\mathrm{CC}$ tracking failure group than in the successful tracking group. Multivariate logistic regression analysis revealed that severe collateral tortuosity (odds ratio [OR]: 13.241, 95\% confidence interval [CI]: 3.429-27.057, $\mathrm{p}=0.038$ ), CC entry angle of $<90^{\circ}$ (OR:4.921, 95\% CI: 1.128-9.997, $\mathrm{p}=0.002$ ), CC exit angle of $<90^{\circ}$ (OR:5.037, 95\% CI: 2.237-11.182, $\left.\mathrm{p}=0.004\right)$, use of Finecross MG as initial microcatheter (OR:1.826, 95\% CI: 1.127-3.067, $\mathrm{p}=0.035)$, and shunning initial retrograde application of Guidezilla (OR:0.321, 95\% CI: $0.267-0.915, \mathrm{p}=0.024$ ) were variables independently associated with initial microcatheter $\mathrm{CC}$ tracking failure in patients with CTO undergoing retrograde septal CC PCI.

Conclusion: The overall initial microcatheter CC tracking failure was $20.8 \%$. Severecollateral tortuosity, $\mathrm{CC}$ entry, and exit angle of $<90^{\circ}$, use of Finecross MG as initial microcatheter, and shunning initial retrograde application of Guidezilla were variables independently associated with initial microcatheter $\mathrm{CC}$ tracking failure in patients with CTO undergoing retrograde septal PCI.

Keywords: coronary chronic total occlusion, retrograde microcatheter tracking, collateral channel, predictor

\section{Introduction}

Chronic total occlusion (CTO) lesions occur in 16-18\% of patients with coronary artery disease undergoing coronary angiography. ${ }^{1,2}$ Before the introduction of the retrograde approach, the success rate of revascularization of CTO lesions was approximately $70 \%{ }^{3}$ However, with the improved devices and new techniques, particularly 
the introduction of the retrograde approach, the current success rate of CTO-PCI performed by experienced cardiologists is more than $90 \%$.An increasing number of studies have demonstrated that successful revascularization can alleviate angina symptoms and improve quality of life as well as ventricular function. ${ }^{4-6}$ Researchers have proposed several models to predict the success of CTO-PCI. The most widely used model in clinical practice is the Japanese Multicenter CTO Registry (J-CTO) score, ${ }^{7}$ which has good predictive value for antegrade success rate. However, the main retrograde intervention technique is the passing of the guidewire and subsequently, the microcatheter. This prediction model does not include factors associated with CC tracking factors, which leads to discrepancies in the predictive value for the success rates of retrograde and hybrid approaches.

Collateral circulation includes septal and epicardial collateral circulations. The core of retrograde interventional therapy is microcatheter tracking after successful guidewire tracking. In some cases, even if the guidewire passes through, retrograde microcatheter coronary channel tracking remains a challenge. To the best of our knowledge, data on the incidence, predictors, and strategies for failure of retrograde microcatheter CC tracking after successful wiring of septal CC are limited. Moreover, the strategies for microcatheter $\mathrm{CC}$ tracking failure have not been well elucidated.

\section{Methods}

\section{Study Population}

From January 2015 to May 2019, we consecutively enrolled 298 patients with CTO who underwent retrograde septal CC intervention in the People's Hospital of Liaoning Province. The patients either failed with antegrade interventional therapy or had good retrograde collateral circulation and a high chance of success with primary retrograde interventional therapy. Patients with New York Heart Association (NYHA) class IV and history of CABGwere excluded from this study. All the study procedures were performed by Bo Luan (corresponding author). All patients received loading doses of aspirin $300 \mathrm{mg}$ and clopidogrel $300 \mathrm{mg}$ (or ticagrelor $180 \mathrm{mg}$ ) before the procedure, followed by aspirin 100 $\mathrm{mg}$ once daily and clopidogrel $75 \mathrm{mg}$ once daily (or ticagrelor $90 \mathrm{mg}$ twice daily) as a dual antiplatelet treatment regimen. The routine access route of the procedure was the radial artery, and the physician determined the access as needed. During the procedure, a standard unfractionated heparin dose $(100 \mathrm{IU} / \mathrm{kg})$ was administered as an anticoagulant therapy, and $2000 \mathrm{IU}$ of unfractionated heparin was added every hour to ensure that the activated clotting time was maintained at $300-350 \mathrm{~s}$. The use of glycoprotein IIb/IIIa inhibitor after the procedure was left to the physician's discretion. The study was approved by the institutional review board of the People's Hospital of Liaoning Province. The study was conducted in accordance with the Declaration of Helsinki, and all the patients signed an informed consent form before participating in this study.

\section{Definitions}

CTO was defined as thrombolysis in myocardial infarction (TIMI) grade 0 flow with a duration of more than 3 months, documented angiographically or clinically defined. ${ }^{8}$ CC grade was defined by Werner as follows: $\mathrm{CC} 0$, no continuous connection between the donor and recipient vessels; $\mathrm{CC} 1$, continuous thread-like connection and $\mathrm{CC} 2$, continuous, small side branch-like connection. ${ }^{9}$ $\mathrm{CC}$ tortuosity was defined as the presence of more than two successive curves (within $2 \mathrm{~mm}$ ) being more than $180^{\circ}$ within a segment length and $<3$ times the diameter of the collateral channel. ${ }^{10}$ Adverse channel entry and exit angles were defined using a cutoff angle of $<90^{\circ} .{ }^{10}$ To evaluate the difficulty of antegrade PCI, the J-CTO score was applied. ${ }^{7}$

Retrograde guidewire success was defined as the passing of the guidewire through the CC into the distal occluded segment without causing severe complications. Microcatheter tracking success was defined as the passing of the microcatheter through the CC to the distal occluded segment without causing severe complications. Procedural success was defined as a residual stenosis of $<30 \%$ after successful stent implantation with TIMI3 blood flow, without causing severe complications. Severe complications were defined as coronary perforation, dissection, hematoma, cardiac arrest, and cardiac tamponade requiring pericardiocentesis. The imaging data for the initial attempt to pass the guidewire through the $\mathrm{CC}$ were recorded in detail and evaluated by two senior cardiologists. A third expert was sought to resolve differing opinions.

\section{Interventional Procedures}

Procedural access was determined by the operator. Bilateral angiography was performed for all the patients to comprehensively evaluate the CTO lesions and the collateral circulation. The selection of collateral circulation and the use and replacement of guidewires were decided by the operator. First, a floppy wire carrying a 
150-cm microcatheter was used to enter the CC ostial. When the guidewire reached the distal end of the occluded segment through the $\mathrm{CC}$, the microcatheter was advanced to the distal end of the occluded segment, and then the retrograde guidewire was selected at the operator's decision. For short lesions, retrograde wire crossing can be attempted. For long lesions, reverse controlled antegrade or retrograde subintimal tracking (CART) can be adopted.

\section{Statistical Analyses}

The Statistical Package for Social Sciences (SPSS) for Windows 20 (IBM SPSS Inc., Chicago, IL) was used for the statistical analyses. Normally distributed continuous data are described as mean \pm standard deviation, and those that were not normally distributed are shown as median (range). Categorical variables are shown as numbers and percentages. To compare the continuous variables, the Student t-test or Mann-Whitney $U$-test was performed. To compare the categorical variables, the chi-square and Fisher exact tests were used. Regression analysis was used to detect the predictors of successful retrograde microcatheter tracking. A univariate regression model was used separately for each of the following covariates: $\mathrm{CC} 0-1$, severe collateral tortuosity, CC entry angle of $<90^{\circ}, \mathrm{CC}$ exit angle of $<90^{\circ}$, use of Finecross MG as initial microcatheter, and shunning initial retrograde application of GUIDEZILLA $^{\mathrm{TM}}$ (BostonScientific, Marlborough, MA, USA). Covariates that showed a significant association with initial microcatheter $\mathrm{CC}$ tracking failure were subjected to a multivariate logistic regression analysis to confirm the variables independently associated with initial microcatheter $\mathrm{CC}$ tracking failure in patients with $\mathrm{CTO}$ undergoing PCI. All the tests were two-sided, and $\mathrm{p}$ values of $<0.05$ were considered statistically significant.

\section{Results}

\section{Baseline Characteristics}

A total of 298 patients with CTO who received retrograde septal intervention were included in this study. The initial microcatheter tracking success rate was $79.2 \%$. No significant differences in age, sex, body mass index (BMI), diabetes mellitus, hypertension, dyslipidemia, smoking history, previous myocardial infarction (MI), NYHA class II or III on admission, and left ventricular ejection fraction (LVEF) were found between the two groups $(\mathrm{p}>0.05$; Table 1).

\section{Procedural Characteristics and In- Hospital Major Adverse Cardiac and Cerebral Events in the Study Population}

Angiography results showed no significant differences in previous failure rate in antegrade $\mathrm{PCI}$, incidence of instent CTO, J-CTO score, and Werner score of $0-1$ $(p>0.05)$. There was no significant difference in initial attempt wire CC tracking success and procedural success rate $(p>0.05)$. The Sion guidewire was used for the initial guidewire $\mathrm{CC}$ tracking and the initial guidewire success rate was $78.5 \%$ (234/298). We found no significant differences in the initial guidewire success rate between the failure and successful groups $(72.6 \%$ vs $80.1 \%, p=0.224$; Table 2). Of the 28 patients who failed in retrograde PCI, 10 successfully received antegrade PCI. The final procedural success rate was $94.0 \%$ (280/298), with a direct guidewire passing rate of $5.4 \%$ (15/280), antegrade PCI rate of 3.6\% (10/290), kissing wire passing rate of $11.4 \%$ (32/280), and reverse CART success rate of $79.6 \%$ (223/ 280) (Figure 1). Among the 64 patients who failed initial guidewire tracking, the guidewire was switched to Fielder XT-R or Sion Black. Finally, the guidewire was passed through the $\mathrm{CC}$ to the distal end of the occluded segment in all 64 individuals (Figure 2).

We found no significant differences in the incidence rates of procedural complications and in-hospital MACCEs. Five $(2.1 \%)$ and two patients (3.2\%) in the successful and failure groups, respectively, developed donor vessel dissection, of whom three (1.3\%) and one patient (1.6\%) had stents implantation, respectively. Septal hematoma occurred in two $(0.8 \%)$ and one patient $(1.6 \%)$ in the successful and failure groups, respectively. Three patients $(1.3 \%)$ in the successful group developed target vessel perforation, and $2(0.8 \%)$ developed acute cardiac tamponade, of whom $1(0.4 \%)$ died after treatment failure. One patient (1.6\%) in the failure group developed target vessel perforation and died after treatment failure. Three patients (1.3\%) in the successful group developed acute in-stent thrombosis and underwent target-vessel revascularization, of whom one $(0.4 \%)$ who had a refractory hypotension died in the hospital. One patient $(1.6 \%)$ in the failure group developed acute in-stent thrombosis, and symptoms were alleviated after target-vessel revascularization (Table 2).

The RCA to LAD septal ratio $(48.4 \%$ vs $33.1 \%$, $\mathrm{p}=0.037)$ and $\mathrm{CC}$ tortuosity ( $34.6 \%$ vs $20.8 \%, \mathrm{p}=0.045)$ in the initial microcatheter $\mathrm{CC}$ tracking failure group were 
Table I Clinical Characteristics of Study Population

\begin{tabular}{|l|l|l|l|}
\hline Variables & Successful Group (n=236) & Failed Group (n=62) & P-value \\
\hline Age(years) & $63.5 \pm 9.2$ & $64.2 \pm 8.9$ & 0.719 \\
Gender(female), $\mathrm{n}(\%)$ & $102(43.2 \%)$ & $21(33.9 \%)$ & 0.195 \\
Body mass index (Kg/m $\left.{ }^{2}\right)$ & $22.3 \pm 3.1$ & $23.2 \pm 3.3$ & 0.628 \\
Diabetes Mellitus, $\mathrm{n}(\%)$ & $87(36.9 \%)$ & $20(32.3 \%)$ & 0.554 \\
Hypertension, $\mathrm{n}(\%)$ & $78(33.1 \%)$ & $19(30.6 \%)$ & 0.763 \\
Dyslipidaemia on admission, $\mathrm{n}(\%)$ & $108(45.8 \%)$ & $33(53.2 \%)$ & 0.319 \\
Current smoker, $\mathrm{n}(\%)$ & $99(41.9 \%)$ & $28(45.2 \%)$ & 0.667 \\
Previous MI, $\mathrm{n}(\%)$ & $90(38.1 \%)$ & $18(29.0 \%)$ & 0.235 \\
LVEF(\%) & $41.6 \pm 6.7$ & $42.2 \pm 7.1$ & 0.417 \\
NYHA 2-3 on admission, $\mathrm{n}(\%)$ & $170(72.0 \%)$ & $42(67.7 \%)$ & 0.530 \\
\hline
\end{tabular}

Abbreviations: MI, myocardial infarction; LVEF, left ventricular ejection fraction; NYHA, New York Heart Association.

significantly higher than those in the successful group (Table 2).

\section{Retrograde Microcatheter CC Tracking}

The overall success rate of initial microcatheter tracking was $79.2 \%$ (236/298). A univariate regression model was used separately for each of the following covariates: $\mathrm{CC} 0$ 1 , severe collateral tortuosity, $\mathrm{CC}$ entry angle of $<90^{\circ}, \mathrm{CC}$ exit angle of $<90^{\circ}$, use of Finecross $\mathrm{MG}$ as initial microcatheter, and shunning initial retrograde application of Guidezilla. Covariates that showed significant associations with initial microcatheter $\mathrm{CC}$ tracking failure were subjected to a multivariate logistic regression analysis to confirm the variables independently associated with initial microcatheter CC tracking failure. Results showed that severe collateral tortuosity (OR: $13.241,95 \%$ CI: 3.429 27.057, $\mathrm{p}=0.038$ ), $\mathrm{CC}$ entry angle of $<90^{\circ}$ (OR:4.921, $95 \%$ CI: $1.128-9.997, \mathrm{p}=0.002), \mathrm{CC}$ exit angle of $<90^{\circ}$

Table 2 Procedural Characteristics and in Hospital MACCE of the Study Population

\begin{tabular}{|c|c|c|c|}
\hline Variables & Successful Group (n=236) & Failed Group $(n=62)$ & P-value \\
\hline \multicolumn{4}{|l|}{ Procedural characteristics } \\
\hline Radial artery+ Femoral artery & $184(78.0 \%)$ & $46(74.2 \%)$ & 0.610 \\
\hline Two femoral arteries & $52(22.0 \%)$ & $16(25.8 \%)$ & \\
\hline Previously antegrade failed, $n(\%)$ & $65(27.5 \%)$ & $12(19.4 \%)$ & 0.253 \\
\hline In-stent CTO, n(\%) & $24(10.2 \%)$ & $5(8.1 \%)$ & 0.810 \\
\hline LAD-CTO, n(\%) & $158(66.9 \%)$ & $32(51.6 \%)$ & 0.037 \\
\hline CC tortuosity, n(\%) & $49(20.8 \%)$ & $18(34.6 \%)$ & 0.045 \\
\hline J-CTO score & $2.5 \pm 0.8$ & $2.6 \pm 0.9$ & 0.371 \\
\hline Werner score 0-I, n(\%) & $52(22.0 \%)$ & II(I7.7\%) & 0.600 \\
\hline Initial Corsair usage, $n(\%)$ & $150(63.6 \%)$ & $20(32.3 \%)$ & $<0.001$ \\
\hline Initial retrograde application of Guidezilla, n(\%) & $117(49.6 \%)$ & $21(33.9 \%)$ & 0.032 \\
\hline First attempt wire CC tracking success, $\mathrm{n}(\%)$ & $189(80.1 \%)$ & $45(72.6 \%)$ & 0.224 \\
\hline Procedural success, $n(\%)$ & $222(94.1 \%)$ & $58(93.5 \%)$ & 0.773 \\
\hline Donor vessel dissection, $\mathrm{n}(\%)$ & $5(2.1 \%)$ & $2(3.2 \%)$ & 0.638 \\
\hline CC hematoma, $n(\%)$ & $2(0.8 \%)$ & $\mathrm{I}(\mathrm{I} .6 \%)$ & 0.505 \\
\hline Target vessel perforation, $\mathrm{n}(\%)$ & $3(1.3 \%)$ & $\mathrm{I}(\mathrm{I} .6 \%)$ & I \\
\hline Cardiac tamponade, $\mathrm{n}(\%)$ & $2(0.8 \%)$ & $\mathrm{I}(\mathrm{I} .6 \%)$ & 0.505 \\
\hline \multicolumn{4}{|l|}{ In hospital MACCE } \\
\hline All cause mortality, n(\%) & $2(0.8 \%)$ & $\mathrm{I}(\mathrm{I} .6 \%)$ & 0.505 \\
\hline Acute in-stent thrombosis, $n(\%)$ & $3(1.3 \%)$ & $\mathrm{I}(\mathrm{I} .6 \%)$ & I \\
\hline TVR, $n(\%)$ & $3(1.3 \%)$ & $\mathrm{I}(\mathrm{I} .6 \%)$ & I \\
\hline
\end{tabular}

Note: Bold values are statistically significant $(p<0.05)$.

Abbreviations: CTO, chronic total occlusion; LAD, left anterior descending artery; RCA, right coronary artery; CC, collateral channels; MACCE, major adverse cardiac and cerebral events; TVR, target vessel revascularization. 


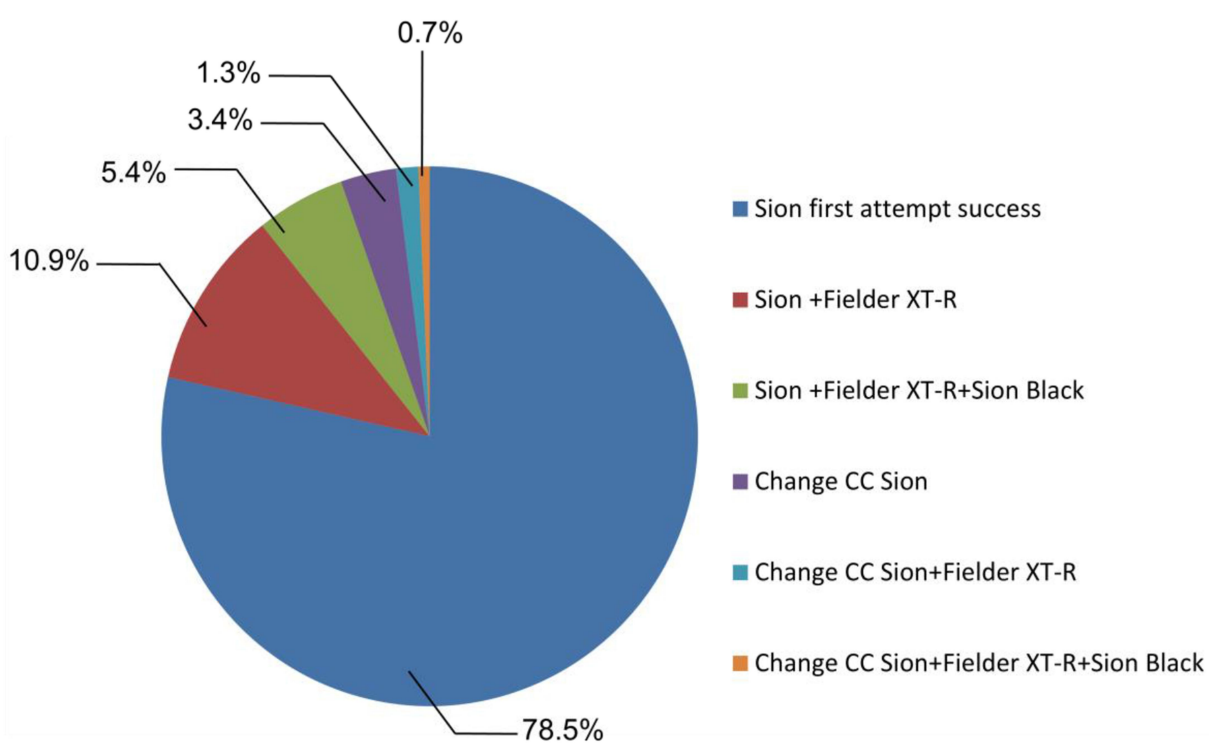

Figure 2 Clinical management of guidewire collateral channel tracking.

(OR:5.037, 95\% CI: 2.237-11.182, $\mathrm{p}=0.004$ ), use of Finecross $\mathrm{MG}$ as initial microcatheter (OR:1.826, 95\% CI: $1.127-3.067, \mathrm{p}=0.035)$, and shunning initial retrograde application of Guidezilla with strong support (OR:0.321, 95\% CI: $0.267-0.915, \mathrm{p}=0.024)$ were variables independently associated with initial microcatheter CC tracking failure in the patients with CTO who were undergoing retrograde septal PCI (Table 3). Among the 62 patients with failed initial microcatheter CC tracking, Guidezilla enhanced retrograde support, microcatheter switching, and balloon dilatation were used, and a microcatheter was successfully inserted in the distal end of the occluded segment in 52 patients (Figure 3). Finally, the success rate of microcatheter tracking was $96.6 \%$.

\section{Discussion}

Septal or epicardial CC can be used for retrograde intervention in patients with CTO. Previous studies have demonstrated that septal $\mathrm{CC}$ is safer than epicardial CC. Guidewire tracking success plays a crucial role in retrograde CTO-PCI. ${ }^{7}$ Previous studies showed that vessel size, severe collateral tortuosity, side branch at $\mathrm{CC}$ tortuosity, inadequate $\mathrm{CC}$ exit, and Werner CC score were predictors of retrograde wire CC tracking failure. ${ }^{11-13}$ In some cases, even if the guidewire passes through, retrograde microcatheter coronary channel tracking remains a challenge. To the best of our knowledge, data on this issue are limited. This study proved that even though the initial microcatheter tracking success rate was only $79.2 \%$, the final microcatheter success rate was

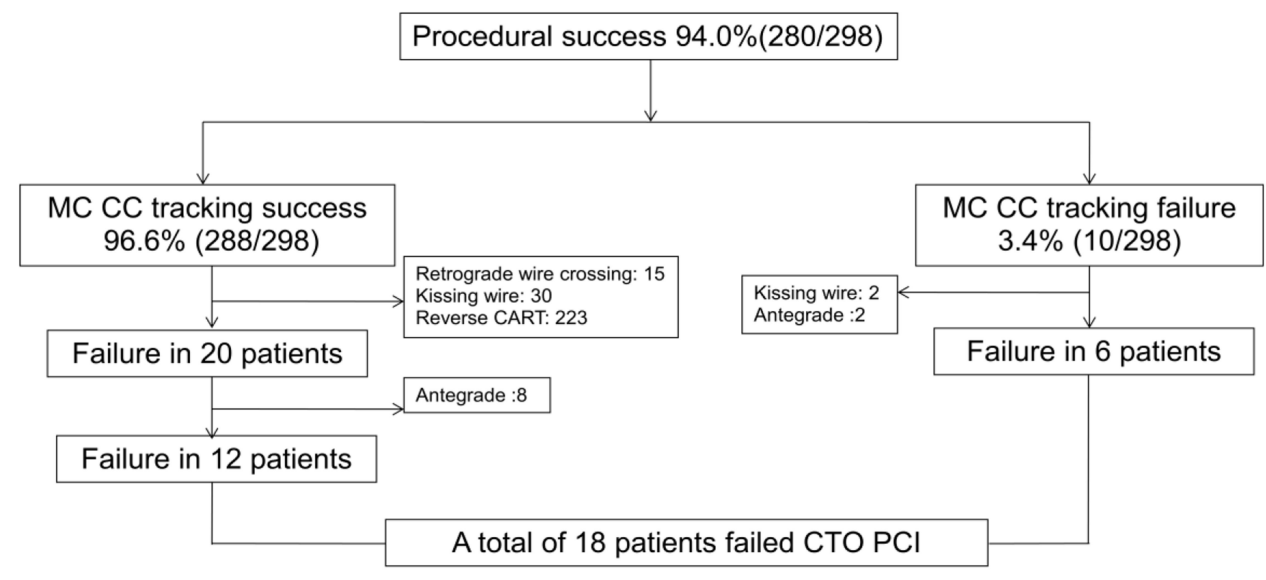

Figure I Clinical management of procedure.

Abbreviations: MC, microcatheter; CC, collateral channels; CART, controlled antegrade and retrograde tracking. 
Table 3 Univariable and Multivariable Analyses for Angiographic Predictors of Initial Microcatheter CC Tracking Failure in Septal and Epicardial Collaterals

\begin{tabular}{|l|l|l|l|l|l|l|}
\hline \multirow{2}{*}{} & \multicolumn{2}{l|}{ Univariate Analysis } & \multicolumn{2}{l|}{ Multivariate Analysis } \\
\cline { 2 - 7 } & $\mathbf{O R}$ & $\mathbf{9 5 \%} \mathbf{C l}$ & $\mathbf{P}$ value & $\mathbf{O R}$ & $\mathbf{9 5 \%} \mathbf{C l}$ & $\mathbf{P}$ value \\
\hline CC 0-I collaterals & 1.802 & $0.617-2.123$ & 0.816 & - & - & - \\
Severe collateral tortuosity & 12.102 & $3.207-26.124$ & $\mathbf{0 . 0 2 4}$ & 13.241 & $3.429-27.057$ & $\mathbf{0 . 0 3 8}$ \\
CC entry angle $<90^{\circ}$ & 4.826 & $1.364-9.197$ & $\mathbf{0 . 0 3 1}$ & 4.921 & $1.128-9.997$ & $\mathbf{0 . 0 0 2}$ \\
CC exit angle $<90^{\circ}$ & 5.112 & $2.425-10.089$ & $\mathbf{0 . 0 4 0}$ & 5.037 & $2.237-11.182$ & $\mathbf{0 . 0 0 4}$ \\
Finecross MG as initial microcatheter & 1.968 & $1.320-2.907$ & $\mathbf{0 . 0 3 2}$ & 1.826 & $1.127-3.067$ & $\mathbf{0 . 0 3 5}$ \\
Initial retrograde application of Guidezilla with strong support & 0.383 & $0.208-0.829$ & $\mathbf{0 . 0 2 7}$ & 0.321 & $0.267-0.915$ & $\mathbf{0 . 0 2 4}$ \\
RCA-LAD CC & 1.369 & $0.803-2.019$ & $\mathbf{0 . 6 2 7}$ & & & \\
\hline
\end{tabular}

Note: Bold values are statistically significant $(\mathrm{P}<0.05)$.

Abbreviations: CC, collateral channels; RCA, right coronary artery; LAD, left anterior descending artery.

$96.6 \%$ after management. This is similar to a recent study, which discovered that initial microcatheter septal tracking failure was $22.5 \%$ in retrograde CTO-PCI ${ }^{14}$ Previous studies demonstrated that the anatomical characteristics of $\mathrm{CC}$ are crucial factors that affect microcatheter tracking; ${ }^{10}$ however, few studies have focused on the management of microcatheter tracking failure after successful guidewire passing. This study found that anatomical characteristics, including severe collateral tortuosity $\mathrm{CC}$ entry angle $<90^{\circ}$ and $\mathrm{CC}$ exit angle of $<90^{\circ}$, were variables independently associated with initial microcatheter CC tracking failure in patients with CTO who were undergoing retrograde septal PCI. Some studies suggested that $\mathrm{CC}$ grades of 0 or 1 are predictors of guidewire passing failure. ${ }^{12}$ However, our results suggest that this is not a predictor of microcatheter tracking failure. We noticed that even in $\mathrm{CC}$ grades 0 and 1, the use of surfing technique can sometimes enable the guidewire and microcatheter to easily pass through the CC. Furthermore, previous studies proved that surfing is effective and safe in retrograde septal PCI. ${ }^{15}$ Therefore, we speculate that a straighter path is more important than the CC grade in septal CC.

In addition, the choice of Finecross $\mathrm{MG}$ as initial microcatheter does not facilitate initial success. We speculate that different microcatheters have different characteristics.For example, the Corsair microcatheter acts as both a microcatheter and channel dilator, which leads to a higher success rate of retrograde intervention, ${ }^{16}$ whereas theFinecross $\mathrm{MG}$ catheter does not have a $\mathrm{CC}$ dilation function. This also explains why Finecross $\mathrm{MG}$ as initial microcatheter is a predictor of microcatheter tracking failure.

Retrograde guiding support is an important factor for successful microcatheter tracking. This could explain why initial use of Guidezilla is a predictor of microcatheter passage. At the same time, the entry of guidewire from the RCA to the LAD collateral circulation is difficult because of poor right coronary artery support, more tortuous collateral and small entry angel. Although the proportion of patients with RCA-to-LAD collateral circulation was significantly higher in the failure group than in the successful group, this study did not find that RCA-LAD collateral circulation is a predictor for microcatheter tracking failure. We speculate that this is due to the strong guiding support in the right coronary artery during the procedure,such as AL1.0, and at the same time,Guidezillawas used in some cases. Meanwhile, guidewire entry may pull the $\mathrm{CC}$ to be straighter, which may therefore facilitate the passage of the microcatheter. This can partially explain why this study found that the RCA-toLAD collateral circulation is not a predictor of microcatheter tracking failure.

Previous studies demonstrated that retrograde septal PCI has high efficacy and safety. ${ }^{17} \mathrm{~A}$ meta-analysis proved that the incidence of vascular perforation and cardiac tamponade in retrograde PCI was $6.9 \%$ and $1.4 \%$, respectively. ${ }^{18}$ However, with technical improvements and device development, the incidence of these complications has gradually decreased in recent years, and the success rate has significantly increased. This study found that the overall success rate of retrograde septal CTO-PCI was $94.0 \%$, and the incidence of cardiac tamponade and perforation were $1.0 \%$ and $1.3 \%$, respectively. This further proved that retrograde septal CTO-PCI is effective and safe. Among the 10 patients with microcatheter tracking failure, 2 underwent kissing wire technique and 2 underwent antegrade PCI. However, the remaining patients failed PCI after various attempts. Even if the retrograde microcatheter was successfully tracked, still 12 patients had failed interventional treatment. The main reason is that the J-CTO scores of the patients enrolled in 


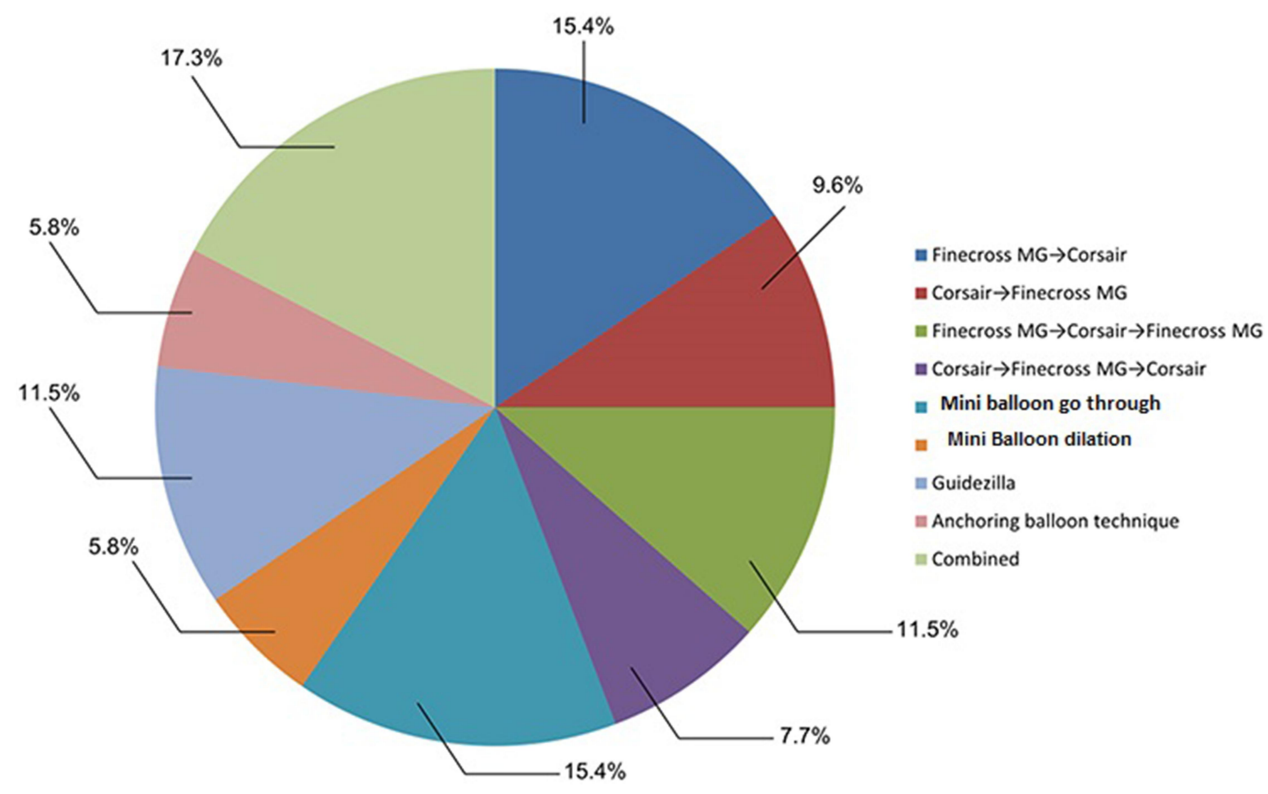

Figure 3 Clinical management of microcatheter collateral channel tracking.

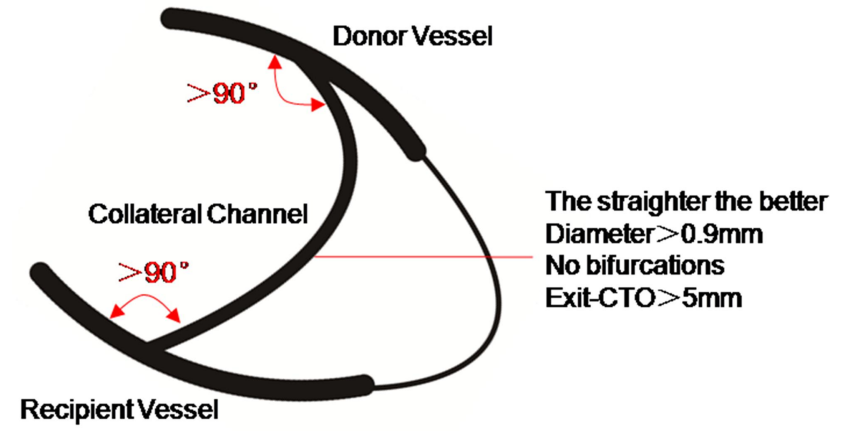

Figure 4 The principle of collateral circulation selection.

this study were high, and a considerable number of patients had failed antegrade PCI.

On the basis of this study and past experiences, we summarize the principles of the septal CC tracking technique as follows:1.The straighter the better; 2 .TheCC entry and exit angles should be greater than $90^{\circ} ; 3$. The $\mathrm{CC}$ diameter should be $>0.9 \mathrm{~mm}$ (comparable with the internal diameter of the Corsair microcatheter). 4 . The distance of the exit to the occluded segment should be more than $5 \mathrm{~mm}$. The Sion guidewire is preferred for septal CC tracking. The Fielder XT-R and Sion Black guidewires could be used for tortuous branches (Figure 4).

With regard to microcatheter tracking failure after guidewire passing, we summarize previous studies and past experiences as follows: 1) enhancing retrograde guiding support, including strong guiding support and Guidezilla insertion; 2) switching the microcatheter from Finecross
MG to Corsair or vice versa; 3) balloons go through or low-pressure dilation; 4) antegrade balloon anchoring in the guiding after the guidewire has passed through the occluded segment; 5) changing the collateral vessels, and 6) changing the strategy. For short lesions, kissing wire or antegrade intervention can be attempted.

\section{Limitations}

The patients included in this study were from a single center and treated by the same operator; therefore, the sample size was relatively small, and there was a selection bias. At the same time, each operator had their own unique learning curve. The study patients were recruited from January 2015 to May 2019, while the procedure success rate has been increasing annually with an increase in the number of procedures and progress in instruments, which resulted in different success rates between the patients treated earlier and those treated later, which might have affected the study results. The J-CTO scores of the study patients were relatively high and not applicable to all study populations. In the future, data from large-scale multicenter studies conducted by highly experienced centers and operators are needed to verify our conclusions.

\section{Conclusion}

The overall initial microcatheter CC tracking failure was $20.8 \%$. Severe collateral tortuosity, CC entry and exit angle of $<90^{\circ}$, use of Finecross $\mathrm{MG}$ as initial 
microcatheter, and shunning initial retrograde application of Guidezilla were variables independently associated with initial microcatheter $\mathrm{CC}$ tracking failure in patients with CTO undergoing retrograde septal PCI.

\section{Abbreviations}

$\mathrm{CC}$, collateral channel; CTO, coronary chronic total occlusion; TIMI, thrombolysis in myocardial infarction; CART, controlled antegrade or retrograde subintimal tracking; LVEF, left ventricular ejection fraction; MACCE, major adverse cardiac and cerebral events.

\section{Data Sharing Statement}

The data supporting the results of the present study are available from the corresponding authors upon reasonable request.

\section{Ethics Approval and Informed Consent}

The study was approved by the ethics committee of the People's Hospital of China Medical University, and all the subjects provided their written informed consent before participation.

\section{Acknowledgment}

We would like to thank Dr Yue-long Niu from The People's Hospital of Cangzhou City for figure drafting.

\section{Author Contributions}

All authors contributed to the data analysis and drafting or revising of the manuscript, provided final approval of the version to be published, and agreed to be accountable for all aspects of the work.

\section{Disclosure}

The authors report no conflicts of interest in this work.

\section{References}

1. Fefer P, Knudtson ML, Cheema AN, et al. Current perspectives on coronary chronic total occlusions: the Canadian multicenter chronic total occlusions registry. J Am Coll Cardiol. 2012;59(11):991-997. doi:10.1016/j.jacc.2011.12.007

2. Ramunddal T, Hoebers LP, Henriques JP, et al. Prognostic impact of chronic total occlusions: a report from SCAAR (Swedish Coronary Angiography and Angioplasty Registry). JACC Cardiovasc Interv. 2016;9(15):1535-1544.

3. Noguchi T, Miyazaki MDS, Morii I, et al. Percutaneous transluminal coronary angioplasty of chronic total occlusions. Determinants of primary success and long-term clinical outcome. Catheter Cardiovasc Interv. 2000;49(3):258-264. doi:10.1002/(SICI)1522726X(200003)49:3<258::AID-CCD7>3.0.CO;2-L
4. Galassi AR, Sianos G, Werner GS, et al. Retrograderecanalizationof chronic total occlusions in europe: procedural, In-Hospital, and longTermoutcomes from the multicenter ERCTO registry. $\mathrm{J} \mathrm{Am}$ Coll Cardiol. 2015;65(22):2388-2400.

5. Jang WJ, Yang JH, Choi SH, et al. Long-term survival benefit of revascularization compared with medical therapy in patients with coronary chronic total occlusion and well-developed collateral circulation. JACC Cardiovasc Interv. 2015;8(2):271-279. doi:10.1016/j. jcin.2014.10.010

6. Tomasello SD, Boukhris M, Giubilato S, et al. Strategies in patients affected by chronic total occlusions: results from the Italian registry of chronic total occlusions. Eur Heart J. 2015;36(45):3189-3198. doi:10.1093/eurheartj/ehv450

7. Morino Y, Abe M, Morimoto T, et al. Predicting successful guidewire crossing through chronic total occlusion of native coronary lesions within 30 minutes: the J-CTO (multicenter CTO registry in Japan) score as a difficulty grading and time assessment tool. JACC Cardiovasc Interv. 2011;4(2):213-221. doi:10.1016/j.jcin.2010. 09.024

8. Stone GW, Kandzari DE, Mehran R, et al. Percutaneous recanalization of chronically occluded coronary arteries: a consensus document: part I. Circulation. 2005;112(15):2364-2372. doi:10.1161/ CIRCULATIONAHA.104.481283

9. Werner GS, Ferrari M, Heinke S, et al. Angiographicassessmentofcollateralconnections in comparison with invasively determined collateral function in chronic coronary occlusions. Circulation. 2003;107(15):1972-1977. doi:10.1161/01. CIR.0000061953.72662.3A

10. McEntegart MB, Badar AA, Ahmad FA, et al. The collateral circulation of coronary chronic total occlusions. Euro Intervention. 2016;11 (14):e1596-1603. doi:10.4244/EIJV11I14A310

11. Huang CC, Lee CK, Meng SW, et al. Channel size and tortuosity predict retrograde percutaneous coronary intervention success for chronic total occlusion. Circ Cardiovasc Interv. 2018;11(1): e005124. doi:10.1161/CIRCINTERVENTIONS.117.005124

12. Huang Z, Ma D, Zhang B, et al. Epicardialcollateral channel for retrograded recanalization of chronic total occlusion percutaneous coronary intervention: predictors of failure and procedural outcome. J Interv Cardiol. 2018;31(1):23-30.

13. Rathore $\mathrm{S}$, Katoh $\mathrm{O}$, Matsuo $\mathrm{H}$, et al. Retrograde percutaneous recanalization of chronic total occlusion of the Coronary arteries: procedural outcomes and predictors of success in contemporary practice. Circ Cardio Vasc Interv. 2009;2(2):124-132.

14. Zhong X, Ge L, Ma J, et al. Microcatheter collateral channel tracking failure in retrograde percutaneous coronary intervention for chronic total occlusion: incidence, predictors, and management. Euro Intervention. 2019;15(3):e253-e260. doi:10.4244/EIJ-D-18-01003

15. Dautov R, Urena M, Nguyen CM, et al. Safety and effectiveness of the surfing technique to cross septal collateral channels during retrograde chronic total occlusion percutaneous coronary intervention. Eurointervention. 2017;12:e1859-e1867. doi:10.4244/EIJ-D-1600650

16. Tsuchikane E, Katoh O, Kimura M, et al. The first clinical experience with a novel catheter for collateral channel tracking in retrograde approach for chronic coronary total occlusions. $\mathrm{J} \mathrm{Am} \mathrm{Coll} \mathrm{Cardiol}$ Interv. 2010;3(2):165-171. doi:10.1016/j.jcin.2009.10.026

17. Benincasa S, Azzalini L, Carlino M, et al. Outcomes of the retrograde approach through epicardial versus non-epicardial collaterals in chronic total occlusion percutaneous coronary intervention. Cardiovasc. Revasc Med. 2017;18(6):393-398. doi:10.1016/j.carrev. 2017.03.013

18. El Sabbagh A, Patel VG, Jeroudi OM, et al. Angiographic success and procedural complications in patients undergoing retrograde percutaneous coronary chronic total occlusion interventions: a weighted metal-analysis of 3482 patients from 26 studies. Int $J$ Cardiol. 2014;174(2):243-248. doi:10.1016/j.ijcard.2014.04.004 


\section{Publish your work in this journal}

Clinical Interventions in Aging is an international, peer-reviewed journal focusing on evidence-based reports on the value or lack thereof of treatments intended to prevent or delay the onset of maladaptive correlates of aging in human beings. This journal is indexed on PubMed Central, MedLine, CAS, Scopus and the Elsevier
Bibliographic databases. The manuscript management system is completely online and includes a very quick and fair peer-review system, which is all easy to use. Visit http://www.dovepress.com/ testimonials.php to read real quotes from published authors.

Submit your manuscript here: https://www.dovepress.com/clinical-interventions-in-aging-journal 